\title{
The evolution of student identity: a case of caveat emptor.
}

\author{
MARTIN, L., SPOLANDER, G., ALI, I. and MAAS, B.
}

2014

This is an Accepted Manuscript of an article published by Taylor \& Francis in Journal of Further and Higher Education on 20.09.2012, available online: http://www.tandfonline.com/10.1080/0309877X.2012.722200 


\title{
File For Review
}

\section{The Evolution of Student Identity: A case of caveat emptor}

\begin{abstract}
Engaging students has been seen as the key to promoting their achievement in higher education institutions. However, there is an important stage prior to this; the development of a positive student identity which influences students' motivation to engage. As the student body has evolved from full-time, on campus students entering university straight from school and has embraced adult, part-time and on line learners who also have employment, the transition to a student identity has become less transparent. To encourage part-time students undertaking an undergraduate degree in Social and Health Care Management to engage with each other the course team piloted peer assessment within the programme for a year. This paper informs the debate by providing insight into the students' approach to learning and attainment. It is argued that the culture of compliance and a technocratic approach to task completion increasingly required within the social care and learning sector is antithetical to deep learning. For students to make the transition they need to commit to a student identity in which participation in reflection and critical debate are valued. The challenge is for universities to enable its occurrence by addressing the barriers and stimulating a positive identity for non-traditional students.
\end{abstract}

Key words: student identity; part-time learners; on line learners; social care

\section{Introduction}

In Higher Education student engagement is often seen as a reliable proxy for learning, (Coates 2007) resulting in improved grades (Tross et al 2000). It contributes to general ability 
development and critical thinking (Gellin 2003), student satisfaction (Kuh et al 2007) and cognitive development (Pascarella and Terenzini 2005). The argument has been that if students engage with each other they will achieve more. While recognising this positive correlation, this paper argues that the road to achievement is more complex and a vital aspect of the journey is the formulation of a student identity. When students conformed to the tradition of being full time, on campus and entering directly from school or Further Education College the adoption of a student identity could be assumed as a natural part of the transition to university. But for many students this may no longer the scenario. The formation of a student identity may not be automatic for the growing number of hybrid students who are studying on line, or part time, or returning to study, or juggling an occupation and study.

This paper highlights the importance of student identity in the relationship between engagement and achievement and considers the barriers the hybrid learner experiences in the transition to "studenthood". This debate emanates from a pilot study to introduce peer assessment into an undergraduate programme as a means of improving engagement and thereby student achievement. All of the students involved were adult learners, studying part time and on line and working in the field of social care. At the point of entry to higher education they already had identities based on their life experiences and work which may make them less malleable than students entering straight from school. There are disparate bodies of knowledge relating to engagement and achievement, traditional student identity formation, adult student identity, on line student identity and occupational identity but these issues have not previously been brought together. This paper straddles the chasm between them by applying the conclusions from the pilot study in order to increase understanding of the link between student identity, engagement and achievement. 


\section{Engagement and Achievement}

Two accepted pre-requisites to achievement in humanities subjects are that students are able to undertake deep learning as opposed to surface learning (Biggs 1987; Marton and Saljo 1976) and that they are able to complete a satisfactory assignment; that is they are proficient at both process and task. The skills involved in writing a successful assignment include selection, integration, organisation, evaluation and creativity (Henderson 1980) and it is argued that these skills cannot be taught but need to be developed through active learning which assists cognitive growth (Schweitzer et al 2003).In order for deep learning to take place students need to reflect and examine the relationship between different concepts and issues so as to understand them (Marton and Saljo 1976; Smith and Colby 2007). For this process to take place students need to be engaged behaviourally, emotionally and cognitively (Fredericks et al 2004) and it is the responsibility of the lecturer to encourage a learning environment which engenders this engagement through learning communities and support. When this is done successfully students will achieve; or so it is argued.

The formula is simple; activity plus engagement equals skills development and deep learning. It was a belief in this formula that underpinned the development of an on line undergraduate degree programme in social and health care management. The teaching team was experienced and understood the formula and so designed a programme with synchronous and asynchronous lectures, activities and discussion forums supplemented by tutorials and ongoing support. Within two years the teaching team had major concerns about the students' achievements and could pinpoint their lack of engagement as a viable explanation. 
Engagement refusal is well researched and highlighted as one of the most common problems for participants in on line study (Coombes and Anderson 2006). Becoming a learner is a transitional process for all students requiring them to leave the comfort and safety of what they know in order to enter an environment which emphasises that they do not yet know enough. For on line students the transition can be even more difficult than for on campus students. Hoskins and van Hooff (2005) note that passive participation on line, such as observing the activity within discussion forums, may have a detrimental effect on cognitive growth as students may not process the arguments. So the student's sense of anxiety, isolation and exclusion increases. A solution for the student encountering this painful transition is to remain in their safety zone and not engage as an active student.

\section{Developing Engagement: The Student Experience}

Still believing the formula to be true, the course team determined to take action which would ensure that students engaged, however reluctantly, by introducing summative peer assessment. Thirteen students and four staff were involved in a pilot for this which lasted for an academic year. Seven of the students and all of the staff responded to an evaluative questionnaire to reflect on the contribution of peer assessment to the learning and achievement of the students involved. The limited scale of the pilot prevents firm deductions from the data but the individual experiences are valid and provided indications that the formula may be incomplete and need further development. 
The experience indicated that students who are reluctant to engage voluntarily in a supportive environment are equally reluctant to engage when required to; supporting Lewin's argument that to bring about change we need to address the forces of resistance rather than simply strengthening the driving forces (Lewin 1951). Results suggested that while there were positives in reading other students' work the students had approached peer assessment functionally rather than as an academic learning activity offering the opportunity to learn.

The approaches that generated most discussion within the staff group and underpin the ideas generated for discussion through this paper were the students whose reluctance to participate was related to their perception of themselves in relation to being a student. One student initially refused to participate in the pilot even though it was a requirement to pass the module because "it is not my job", while others who were more compliant saw it as an increase in an already heavy workload as part-time students juggling study with other commitments and expressed relief that on one occasion the peer evaluation had to be cancelled. For most students it was therefore akin to a management type task which needed to be completed; they approached it from their occupational role rather without appreciating the academic merits of comparing their academic development with that of others.

The hypothesis arising from this experience is that student engagement cannot be generated solely by the provision of learning activities but requires the learner to adopt a student identity which will motivate and initiate engagement when opportunities are presented.

\section{Developing a Student Identity}


There is a danger that both educationalists and students can see engagement within a narrow functional focus rather than recognising the importance of student identity in influencing the nature of engagement which in turn affects academic achievement.

Identity is fluid, multi-dimensional and some aspects are selected or temporary. It is argued that the pace of social change has raised the importance of identity (Howard 2000) as we increasingly need to locate ourselves. Frable (1997) encourages an approach which perceives people in entirety rather than as fragmented beings, but in reality compartmentalisation takes place partly through the filtering process of the perceiver but also through the choices made by the perceived as to which identities they choose to reveal (Sampson 1999; Tajfel and Turner 1986). So learners embarking on higher education have some degree of choice as to whether they adopt a student identity.

Social cognition theorists argue that identity is made up of a series of labels devised as a means of categorization; a short-hand communication which has a shared meaning. However, these labels are not value-free and will be perceived as more or less desirable by different individuals within their own context. Symbolic interactionists state that meaning emerges as a result of interaction. In relation to student identity, at a group level this will be moulded by public response and popular discourse and at an individual level through conversation and dialogue. Kaufman and Feldman's (2004) research into the experience of transition from precollege to college recognised the influence of location on the development of student identity.

Whilst marketization has led to the prioritization of engagement for full-time students there is an associated risk of non-traditional students receiving less attention in this area. Universities 
are experienced in applying both of the afore-mentioned theoretical approaches to help students to form a positive student identity. The campus base is utilised to its maximum to ensure that full-time students socialise, learn, shop and play there. Student accommodation is designed to provide opportunities for new entrants to establish new friendships; in the early weeks of transition enjoyment is emphasised and support services are on hand to try to catch those who err from the path towards successful transition. Students are encouraged to develop routines and rituals which will enhance their sense of belonging (Goffman 1969). Being a 'student' is promoted as a positive status, accessible yet privileged; a route to future success and independence, but this persona is less available to non-traditional students.

There is an acceptance that making the transition to becoming a student is difficult and even with all of the opportunities provided to ease the process, some do not succeed. The attrition rate in the first term is known to be at its highest, and Combes and Anderson (2006) suggest that in the early stages of their academic career students feel a greater affinity with face-toface experiences as a means of developing their identity. The challenges for on line students to establish who they are remain even more significant that for the on campus student.

Although with time and commitment students can forge a way forward for themselves, even students who have previous experience of on line activity will go through a familiarisation process which involves dealing with uncertainty and discomfort (Combes and Anderson 2006).

On line students do not have the 'buzz' of the university campus to stimulate their commitment to learn and unless they overcome the hurdles to begin to engage with other students they do not have the discussions to enable them to form a positive student identity. 
Additionally the process of de-individuation which can occur through asynchronous learning threatens their identity development (Sherblom 2010; Wang et al 2009). The premise underpinning this process is that if a learner is in a barren environment bereft of the visual signals which enhance understanding of dialogue and is isolated from social interaction s/he will assume a cloak of anonymity. This may not be worn purposefully but the learner has no opportunity to define her or his individual identity. As this process takes place the learner will assume the identity of the group, but without a detailed knowledge of the group this will be stereotypical. The learner thereby engages less with critical self reflection and more with assumption based on biased interpretation. Ho and McLeod (2005) suggest the individual can carve an individual identity but as asynchronistic interaction can be edited before it is shared this is to some extent manufactured.

The reason that students participating in this particular undergraduate programme chose to study on line is that they are also working and are therefore adult or mature learners. While adult learners can form a very positive identity on campus, this is influenced by their perception of younger students (Kasworm 2005). Her research demonstrated that adult students set high standards of student behaviour for themselves and assessed their success in comparison to traditional students who provided the benchmark. Their views of younger students were positive but they regarded themselves as having made a greater commitment by returning to study and taking more risks by exposing themselves to a learning environment with younger learners. Their drive to be seen to work hard and achieve was therefore high. Their identity developed through meaningful interaction with the younger students and an appreciation of the differences between their own experience and that of the younger students. As noted by Kasworm (2005:16): 
“...these adult students experienced changing student identities influenced by both the complex set of actors and structures of the classroom and college as well as their own selfconstructions of college student behaviours and beliefs and the ongoing dynamics of adult role experiences".

This is not the experience of adult on line learners. They do not have the visual clues about their fellow students that might begin to help them to locate themselves within the student body. It is only if they are able to overcome the barrier to engagement that they will begin to develop more than an assumed stereotypical view of their peers. The student group is unlikely to be traditional in age and it is more likely that adult learners will find themselves alongside other adult learners who are also teetering on the edge, trying to decide whether to dip a toe into studenthood or step back into their other identities.

The observations from the pilot peer assessment project are that students are reluctant to take that step forward or feel unable to. They cannot access the positive view of student life that the on campus student sees; any view they have formed of being a student is based on an assumed view and does not offer the same benefits as it does for the traditional student. Those moving to university from school stand to gain a positive and attractive status shared with their peers while the adult learner in employment already has a valuable role identity which becoming a student may not successfully compete against and which isolates them from their peers. 
For most people working in the health and social care sector their role identity is important. People hope to make a difference to the lives of others and take pride in their work. While the dedication and commitment of those working in this sector continues the role has changed. The advent of New Public Management (NPM) is gradually but significantly affecting the role identity of people working in the public sector (van Bockel 2006; Horton 2006; Wilson et al 2008). Traditionally those working in the public sector have perceived themselves as public servants with an identity that incorporates "honesty, integrity, probity, dispassionateness, freedom from corruption and above all service to the public interest" (Horton 2006: 536). But the foundations of this have been destabilized. Research suggests that in the same way that market forces and competition have led to a diversity of service providers, so there is also a diversity of identity formation. However, it must be remembered that while choice is viewed as a positive in this new regime, inconsistency is not. So the emerging identities of public sector organisations are at one and the same time influenced by competition, entrepreneurial spirit, a drive for results with increased regulation and expectation of compliance (Horton 2006; Osborne and Gaebler 1992; Wilson et al 2008). Performance driven practice has led to some decision-making based on questionable ethics (van Bockel 2006; Dalrymple 2004) and an ideological shift away from the public interest in favour of self-interest.

Increase in regulation brings with it a decrease in autonomy so while organisations may appear to be more individualistic, those delivering the service to the public are not. Child protection services have seen qualified and experienced social workers absorbed into a culture of compliance with an emphasis on ensuring the management of service users' behaviour as opposed to capacity building (Harris 2011), a view which echoes Munro’s concerns that children's services have: 
“...evolved too far into a top-down, compliance-driven organisation. This stifled creativity and distorted priorities, with more attention given to the completion of bureaucratic tasks to specified timescales as the measure of success, than the appraisal of the quality of help received by children and their families" (Munro 2010: 17).

Braithwaite (2002) argued for the use of responsive regulation which challenges the assumption on which regulations are based but as he acknowledges the result would be to increase inconsistency, the polar opposite of the intent of regulation.

With this level of compliance emphasised within the qualified social work population, how much greater must it be within the unqualified workforce, from which the undergraduate social and health care management degree recruits its students?

Few non-professionally qualified staff in frontline residential and care services have a recognised social care qualification. They are frequently in low paid positions (Low Pay Commission 2011) working in environments where there is little supervision and where staffing levels are stretched (Mansell 2011). To manage quality and promote consistency there are regulatory bodies such as the Commission for Social Care Inspection (CSCI) and the Health Professions Council, soon to be renamed the Health and Care Professions Council, in addition to advisory bodies such as the Care Quality Commission (CQC) which reinforce a culture of compliance. Increasingly templates and pro-formas are utilised to direct assessments discouraging independent thinking or behaviour by the individual worker. It is 
this technocratic approach which moulds the worker's role identity prior to their university experience.

It is little wonder that emerging from this environment to a culture of academic learning, these students question whether it is their job to mark the work of other students and question the time spent on completing the task rather than embracing the learning potential. Increasingly achievement is inextricably linked to task completion, standardization, compliance and consistency rather than processes of creativity, reflexivity or individual determination which might be expected to assist achievement in a learning environment. Indeed a managerialist approach may lead workers to perceive learning as a hindrance to organisational achievement (time away from the job) and only of personal benefit. A key reason for adults to return to study is to better their career prospects, so their role identity remains extremely important to them.

Identity is fluid and as individuals we not only have a range of separate identities contributing to a whole, but we move between them with relative ease. However, this movement is not always a considered choice but may be a response to stimuli. Research by Yopyk and Prentice (2005) into the identities of student-athletes in American universities demonstrated how priming the students with either their athlete identity or their student identity before completing a particular task affected the outcome. When primed with their athlete identity they performed less well on a maths test than their peers who were primed with their student identity. Students who were not primed were able to adopt the appropriate identity determined by the task; (this builds on earlier research by Shih et al (1999) into the performance of Asian American women when primed with either their ethnic or gender 
identity). So, when the playing field is even, students are able to make beneficial choices. However for part-time online learners the playing field appears not to be even as they attempt to switch between a dominant role identity and a poorly formed student identity.

\section{The Way Forward}

This paper seeks to encourage debate rather than provide ready-made solutions as there is a need to consider the impact of the marketization of education on different constituents and whether increased emphasis on efficiency challenges equality of opportunity and prioritizes certain values over others. In seeking to understand academic efficiency maybe we need to take a wider view.

In a commendable attempt to recognise the experience that part-time learners bring with them from their work experience and to further enhance the quality of the work they continue to do in their occupation, increasingly higher education programmes prioritise the links between theory and practice. In the course in question all assignments provided the students with an opportunity to write about their work practice. This link is important and is intended to ensure that universities do not produce students who are good critical thinkers but cannot relate their understandings to practice. But for online learners in particular, maybe the balance needs to be addressed. If the students are being continually primed with a work based role identity which emphasises compliance and task completion they will struggle to adopt a positive student identity essential for critical thinking. 
The indications are that the formula for student achievement needs to be expanded; there is a prior stage necessary for successful engagement which is the formation of a positive student identity. The development of student identity will engender activity and engagement which will result in deep learning and skills development leading to student achievement. The challenge is how to enable this shift for adult part-time on line learners who arrive at university with a range of identities which are a stronger influence than the pull of becoming a student.

At a practical level a first step is to develop a first term or semester curriculum which emphasises the new learner's transition to becoming a student. Induction programmes often include a focus on returning to study and developing academic skills but this is not the same as becoming a student. Attention needs to be paid to the value of being a student; the expected behaviour and anticipated experience of those making the transition; the importance of the process of learning and the benefits that await those who make the transition.

Those developing the programme content need to weigh very carefully the balance between building on the practice experience of students while moving them into a more creative, innovative and academic environment, priming them with their student identity rather than their occupational identity.

Finally, universities need to explore ways of reaching out to on line students. This mode of study offers an accessible option for people in employment to enter the world of higher education providing maximum student flexibility (Hoskins and Hooff 2005; Sherman, 1998; 
Ward and Newlands 1998) but universities need to ensure that on line students experience the wide range of services, supports and experiences on offer to the traditional student. This requires some different thinking, bureaucracy-busting and innovative working, but who better to rise to the challenge than those responsible for developing the talent of our future. 


\section{References}

Biggs, J. 1987 Student Approaches to Learning and Studying. Melbourne: Australian Council for Educational Research

Braithwaite, V. 2002 Restorative Justice and Responsive Regulation: Studies in Crime and Public Policy'. Oxford: Oxford University Press

Coates, H. 2007 A model of online and general campus based student engagement. Assessment and Evaluation in Higher Education, 32 (2), 121-141

Combes, B. and Anderson, K. 2006 Supporting First Year E-Learners in Courses for the Information Professions. Journal of Education for Library and Information Science, 47(4), $259-276$

Dalrymple, T. 2004 Levan aan de Onderkant (Life at the Bottom, 2001). Ultrecht: Spectrum Frable, D.E.S. 1997 Gender, Race, Ethnic, Sexual and Class Identities. Annual Review of Psychology, 48, 139-162

Fredericks, J. A. Blumenfeld, P. C. and Paris, A. H. 2004 School Engagement: Potential of the Concept, State of the Evidence. Review of Educational Research, 74 (1): 59-109

Gellin, A. 2003 The Effect of Undergraduate Student Involvement on Critical Thinking: A Meta- Analysis of the Literature, 1991 - 2000. Journal of College Student Development, 44 (6), 746-762

Goffman, E. 1969 The Presentation of self in everyday Life. Harmondsworth: Penguin Harris, N. 2011 Does Responsive Regulation Offer an Alternative? Questioning the Role of Formalistic Assessment in Child Protection Investigations. British Journal of Social work, 41, $1383-1403$ 
Henderson, E.S. 1980 The Essay in Continuous Assessment. Studies in Higher Education, 5, 197-203

Ho, S.S. and McLeod, D.M. 2005 Social-Psychological Influences on Opinion Expression in Face-to-Face and Computer-Mediated Communication. Communication Research, 35, 190207

Horton, S. 2006 New Public Management: Its Impact on Public Servant's Identity International Journal of Public Sector Management, 19(6), 533-542

Hoskins, S.L. and van Hooff, J.C. 2005 Motivation and Ability: Which Students use Online Learning and What Influence does it have on their Achievement? British Journal of Educational Technology, 36(2), 177-192

Howard, J.A. 2000 Social Psychology of Identities. Annual Review of Sociology, 26, 367393

Kasworm, C. 2005 Adult Student Identity in an Intergenerational Community College Classroom. Adult Education Quarterly, 56(1), 3-20

Kaufman, P. and Feldman, K.A. 2004 Forming Identities in College: A Sociological Approach. Research in Higher Education, 45(5), 463-496

Kuh, G. D., Kinzie, J., Buckley, J. A., Bridges, B. K. and Hayek, J. C. 2007 Piecing Together the Student Success Puzzle: Research, Propositions and Recommendations. ASHE Higher Education Report, 32, 5, San Francisco, Jossey- Bass

Lewin, K. 1951 Field Theory in Social Science, New York: Harper and Row Low Pay Commission 2011 National Minimum Wage Low Pay Commission Report 2011, accessed at: 
http://www.lowpay.gov.uk/lowpay/report/pdf/Revised_Report_PDF_with_April_date.PDF, [last accessed 20 June 2011]

Mansell, J, 2011 Bristol care home: a failure on every level, The Guardian, accessed at: http://www.guardian.co.uk/commentisfree/2011/jun/01/bristol-care-home-failure-every-level, [last accessed 20 June 2011]

Marton, F. and Saljo, R. 1976 On Qualitative Differences in Learning. Outcome as a Function of Learners' Conception of Task. British Journal of Educational Psychology, 46, $115-127$

Munro, E. 2010 The Munro Review of Child Protection. Interim report: The Child's Journey. London: DH

Osborne, D. and Gaebler, T. 1992 Reinventing Government: How the Entrepreneurial Spirit is Transforming the Public Sector. Reading, MA: Addison-Wesley

Pascarella, E. T. \& Terenzini, P. T. 2005 How College Affects Students: a Third Decade of Research, vol 2, San Francisco: Jossey-Bass

Sampson, E.E. 1999Dealing with Differences: An Introduction to the Social Psychology of Prejudic., Orlando: Harcourt Brace

Schweitzer, K., Paechter, M. And Weidermann, B. 2003 Blended Learning as a Strategy to Improve Collaborative Task Performance. Journal of Education Media, 28(2-3), 211-224

Sherblom, J.C. 2010 The Computer-Mediated Communication (CMC) Classroom: A Challenge of Medium, Presence, Interaction, Identity, and Relationship. Communication Education, 59(4), 497-523 
Sherman, R.C. 1998 Using the World Wide Web to Teach Everyday Applications of Social Psychology. Teaching of Psychology, 25, 212-216

Shih, M., Pittinsky, T.L. and Ambady, N. 1999 Stereotype Susceptibility: Identity Salience and Shifts in Quantitative Performance. Psychological Science, 10(1), 80-83

Smith, T.W. and Colby, S.A. 2007 Teaching for Deep Learning. The Clearing House, MayJune, 80 (5), 205-6

Tajfel, H. and Turner, J.C. 1986 The Social Identity Theory of Inter-Group Behaviour, in Worchel, S. And Austin, L.W. (eds.), Psychology of Intergroup Relations. Chicago: NelsonHall

Tross, S. A., Harper, J. P., Osherr, L. W. and Kneidinger, L. M. 2000 Not just the Usual Cast of Characteristics: Using Personality to Predict College Performance and Retention, Journal of College Student Development, 41 (3): 325-336

Van Bockel, J. and Noordegraaf, M. 2006 Identifying Identities: Performance-Driven, but Professional Public Managers. International Journal of Public sector Management, 19(6), $585-597$

Wang, Z., Walther, J.B. and Hancock, J. 2009 Social Identification and Interpersonal Communication in Computer-Mediated Communication: What you do Versus Who you are in Virtual Groups. Human Communication research, 35, 59-85

Ward, M. and Newlands, D. 1998 Use of the web in Undergraduate Teaching. Computers and Education, 31, 171-184

Wilson, K., Ruch, G., Lymbery, M. and Cooper, A. 2008 Social work: An Introduction to Contemporary Practice. Harlow: Pearson education 
Yopyk, D.J.A and Prentice, D.A. 2005 Am I an Athlete or a Student? Identity Salience and

Stereotype Threat in Student-Athletes. Basic and Applied Social Psychology, 27(4), 329-336 